\title{
SUBSTANTIATING THE PARAMETERS OF THE PROCESS OF ADDING LIQUID PRESERVATIVES TO PLANT MATERIALS
}

\author{
V.A. Yunin ${ }^{1}$, A. M. Zakharov ${ }^{1}$, N. N. Kuznetsov ${ }^{2}$, A. V. Zykov ${ }^{1}$ and Yu. N. Malinovskaya ${ }^{2}$ \\ ${ }^{1}$ Federal Scientific Agricultural Engineering Center VIM, Moscow, Russian Federation \\ ${ }^{2}$ Federal State Budgetary Educational Institution of Higher Education the Vereshchagin, Schmidt Street, Molochnoye, Vologda City, \\ Russian Federation \\ E-Mail: vim_iaep@mail.ru
}

\begin{abstract}
The leading direction in the technology of harvesting hay of high humidity in rolls is the conservation of its chemicals in the pressing process. The distribution of chemical preservatives in plant materials is based on diffusion, i.e. the transfer of matter from one area to another within one phase without mixing. It has been found that the ratio between the vaporous and liquid phases of chemical preservatives can be characterized by the following data: formic acid - $0.16 \%$; AIV2000 Plus - 0.28\%; propionic acid - 0.25\%. The kinematic diffusion coefficient characterizing the process of distributing preservatives in the stalked plant mass is a constant value that determines the complex (effective) distribution of the vaporous and liquid phases of the preservative.
\end{abstract}

Keywords: liquid preservative, grass feed, technological process, conservation, storage, parameter.

\section{INTRODUCTION}

The effectiveness of applying preservatives in forage preparation depends largely on their uniform distribution in the plant material and on following the given rates of application which imposes strict requirements on technological and structural features of the equipment [1].

The main line in the technology of making hay having increased moisture content in rolls is preserving it with chemicals during pressing. This allows making hay with moisture content of $25-30 \%$, to decrease the time of washing out the nutrients from the plant in unfavorable weather conditions, and in doing so decrease the losses during haymaking and storage. Pure propionic acid and AIV-2000 Plus preparation are useful in preserving hay having increased moisture content. They are strong fungicides, and they block the activity of enzymes regulating cell respiration in plants $[2,3]$.

It is possible to increase the production of hay and improve its quality not only by increasing its yield and developing the botanical composition of plants, but also by using advanced technologies of making and storage of feeds.

Only making hay with high moisture content can decrease mechanical losses. Grass should be partially dried in the field and finally dried in the place of its storage, or be preserved in some other way, which mostly refers to beans losing up to $75 \%$ of the leaves in the process of drying them in the field [4].

In all cases, regardless of haymaking technology, everything must be done to make the process of drying the cut grasses in the field faster to avoid losing nutrients and vitamins due to biochemical processes and biological activity. The longer the mass stays in the field, the greater the losses. So, drying the green mass of grasses for 76 hours, when it was exposed to rain twice, the losses of dry matter were $41 \%$. And for 161 hour of drying in the field, when the grass was exposed to rain 8 times, the losses increased to $12.9 \%[4,5]$.
To decrease the losses of nutrients during making hay in rolls, and to reduce the dependence of haymaking on weather conditions, chemical preservatives suppressing undesirable microorganisms in fodders should be used during storage. In this connection, applying chemical preservatives when a baler picks up the grass dried up to $35 \%$ of moisture content and further presses it into rolls is of great interest. It allows to lower the loss of nutrients by reducing the time when the cut grass stays in the field, and to improve the quality of hay.

The aim of this work is to justify the manner and means of mechanization of applying liquid chemical preservatives on partially dried grass in the process of round baling.

Applying liquid chemical preservatives during haymaking is a complex scientific and practical problem because this process is connected with the simultaneous interaction of several factors including the plant, the chemical preservative, various technical means, the animal organism, and the man. Therefore, it is necessary to consider all the main features to get the greatest biological, industrial, and ecological effect from the interaction of these factors with the least cost of labor and resources.

It is known that generation and storage of the feed mass of plants are the result of biochemical processes in plant cells. It is necessary to support the processes providing accumulating the feed mass in plants and to slow down or stop the processes destroying the nutrients. The former take place in the growing plants, and the latter go on in the cut grass having no access to nutrients from the soil $[5,6]$.

To get high quality vegetable fodder at the same time minimizing the loss of nutrients and bioactive substances, it is necessary to reduce to a minimum the activity of the cells in the cut grass.

The main condition for the activity of plants is their metabolism including two simultaneous processes acting in the opposite directions: assimilation (absorption) and dissimilation (decomposition). In the process of 
www.arpnjournals.com

assimilation the plant builds its own cells using the substances from the external environment, and in the process of dissimilation carbohydrates are split with releasing energy and forming end products.

These biochemical processes are carried out due to enzymes. Therefore, all the methods used to increase the number and to boost the activity of enzymes participating in the processes of assimilation will promote the synthesis of the feed mass, and all the methods used to decrease the number and reduce the activity of enzymes taking part in dissimilation will promote decomposition of substances, and finally the activity will stop.

The interaction between the preservative and the plant cell goes on best in a liquid medium. That's why preservatives should be well soluble in water and in plant juices.

The basis for the process of chemical preservatives distribution in the plant material is diffusion, or carrying substances from one area to another within one phase without stirring. Experiments and theory show that diffusion occurs in the presence of pressure gradient, temperature gradient, fields of external forces, and concentration gradient.

Partially dried plant material in the field in which diffusion takes place is a substrate consisting of stalks and leaves and containing bound moisture and air. The liquid chemical preservative is composed of its own liquid and vapor. The vapor is formed on the surface of the liquid under the action of concentration and temperature gradients. The preservative diffuses in such a medium mainly in two phases: liquid and vaporous (gaseous). The vaporous phase of the chemical preservative diffuses into the external structure of plants with the speed proportionate to the concentration gradient of the diffusing substance. Stalks and leaves are the natural obstacle in the directions of diffusion in the plant; they slow down the process of vapor diffusion.

\section{MATERIALS AND METHODS}

While the vapors of preservatives diffuse in the plant layer, plants absorb moisture and vapor according to the law described by the Brunauer-Emmett-Teller equation for plant materials with moisture content up to $35 \%$ [7].

$$
u_{p}=u_{1} \frac{C \phi}{1-\varphi(2-C)+\varphi^{2}(C-1)}
$$

where: $u_{p}$ - equilibrium moisture content of the material at the corresponding treatment regime, $\mathrm{kg} / \mathrm{kg} ; u_{1} \quad$ equilibrium moisture content of the material before treatment, $\mathrm{kg} / \mathrm{kg} ; \varphi$ - relative humidity of vapor-air mixture, dimensionless; $C$ - constant characterizing the kind of material, dimensionless.

While solving equation 1 for value $u_{p}$ on the condition of maximum humidifying of the plant material with the vapors of the preservative we find that the moisture content of the plants slightly increases, that's why the effect of water absorption from the vapors of the preservative on the preservation process can be neglected. The liquid phase of the preservative interacts with the carriers of protein nature and diffuses inside the plants, where the solvent is the plant juice, and directly participates in the process of fodder acidification.

The processes of vapor and liquid diffusion in plant material are classified as a unidirectional diffusion and are described by the general equation:

$N_{a}=-D\left(\frac{C_{A}+C_{B}}{C_{B}}\right) \cdot \frac{d C_{A}}{d X_{B}}$

where $N_{A}$ - number of moles in substance A diffusing in one direction through the unit of the cross-section in a unit of time, mole; $D$ - kinematic diffusion coefficient, $\mathrm{m}^{2} / \mathrm{s}$; $C_{A}$ - concentration of the diffusing substance, $\mathrm{kg} / \mathrm{m}^{3} ; C_{B}$ - concentration of the diffusing media, $\mathrm{kg} / \mathrm{m}^{3} ; X_{B}$ - length in the direction of diffusion, $\mathrm{m} ; \frac{d C_{a}}{d X_{B}}$ - concentration gradient of the diffusing substance along the $\mathrm{X}$ coordinate. The minus sign before the concentration gradient shows that $C_{A}$ concentration decreases in the direction of diffusion. The greater the resistance met by diffusion of molecules of the substance $\mathrm{A}$, the greater concentration gradient $\frac{d C_{A}}{d X_{B}}$ is. The value of this resistance is proportionate to the concentration of molecules in the medium where diffusion takes place. The higher the resulting speed of molecules in the solvent in the direction opposite to the movement of the substance, the slower the diffusion will be.

Kinematic diffusion factor $D_{A B}$ is a factor of proportionality between the flow of A component and its gradient in the direction of diffusion and is generally defined for gases by the following equation of ChapmanEnskog (Galkin, 2007):

$$
D_{A B}=\frac{3 \pi k T}{8} \sqrt{\left(\frac{M_{A}+M_{B}}{M_{A} M_{B}}\right)} \cdot \frac{1}{n \pi \sigma_{A B}^{2} \Omega_{D}} f_{D} \mathrm{~m}^{2} / \mathrm{s}
$$

where $M_{A}, M_{B}$ - molecular masses of the solved substance and the solvent, $\mathrm{kg} ; \mathrm{n}$ - number of molecules in 1 $\mathrm{m}^{3} ; \mathrm{k}$ - Boltzmann constant; $\mathrm{T}$ - temperature, ${ }^{\circ} \mathrm{C} ; \Omega$ collision integral for diffusion (is the function of temperature and depends on the chosen law of molecular interaction forces of the colliding molecules); $\Sigma_{\mathrm{AB}}$ characteristic distance (it also depends on the chosen law of intermolecular forces); $\mathrm{f}_{\mathrm{D}^{-}}$corrective member having the value of the order 1.0-1.1. 
www.arpnjournals.com

In the case of diffusion of vapors of chemical preservatives through the layer of plant material taking place at the atmospheric pressure and at the temperature of $23^{\circ} \mathrm{C}$ the effect of pressure and temperature on the coefficient is insignificant. That's why Ibrahim and Kuloor found a linear dependency of gas and vapor diffusion into the air on the molecular mass $\mathrm{M}$, and on this basis they suggested the formula (Novoselov 2014):

$\mathrm{D}_{\mathrm{AB}}=\frac{100 \mu V_{M}}{0.122 M-1.3} \mathrm{~m} / \mathrm{s}$

where $\mu$ - a dynamic viscosity index of preservative vapors, Pa.s; $V_{M}$ - molar volume of vapors, $\mathrm{m}^{3} / \mathrm{mole} ; M$ molar mass of vapors, $\mathrm{kg} / \mathrm{mole}$.

In the layer of plant matter with the pressing density of $150 \mathrm{~kg} / \mathrm{m}^{3} \mathrm{on}$ average, the kinematic diffusion coefficient is lower compared to vapor diffusion into the air.

That's why to calculate the diffusion coefficient in the layer of plant material it is suggested to introduce a correction factor $\mu_{c}=1,7$ [9].

Formula 3 based on this coefficient is presented as follows:

$D_{\kappa c}=\frac{D_{A B}}{\mu_{c}}=\cdot \frac{100 \mu V_{\mu}}{(0,122 M-1,3) \mu_{c}}$

where $D_{\kappa c}$ - calculated coefficient of kinematic diffusion of chemical preservative vapors in the environment of plant materials, $\mathrm{m}^{2} / \mathrm{s}$.

The results of calculating $D_{\kappa c}$ coefficients for the vapors of the main liquid preservatives are presented in Table-1.

The vapor and liquid phases of chemical substances are in the equilibrium which is generally described by Clausius-Clapeyron equation [10]:

$\frac{d P_{v p}}{d T}=\frac{\Delta H_{v}}{\left(R T^{2} / P_{v p}\right) \cdot \Delta Z_{v}}$

where $P_{v p}$ - pressure of vapors, $\mathrm{Pa} ; \Delta H_{v}$ - heat of vaporization, $\mathrm{J} / \mathrm{kg} ; R$ - universal gas constant; $T$ temperature, ${ }^{0} K ; Z_{v}$ - vapor compressibility coefficient.

Inserting the values of molar volumes of liquid and vapour into equation 6 we define the heat of vaporization:

$$
\Delta H_{v}=\frac{d P_{v p} T}{d T J}\left(V_{M n}-V_{M \varkappa}\right) \mathrm{J} / \mathrm{kg}
$$

where

$V_{M n} \quad$ - molar volume of vapor, $\mathrm{m}^{3} / \mathrm{mol}$;

$V_{\text {Мж }} \quad$ - molar volume of liquid, $\mathrm{m}^{3} / \mathrm{mol}$;

$J \quad$ - mechanical equivalent of heat.

To calculate the numerical values we'll use the empirical interpretation of equation 7 :

$L_{P c h}=\frac{\left(\frac{\Delta H_{v}}{M}\right)^{4 / 5}}{\frac{1}{V_{M \rightsquigarrow c}}-\frac{1}{V_{M n}}}$

where $L_{P c h}$ - lyoparachor value calculated for chemical preservatives according to Bowden and Jones (Kahr et al., 2015); $\Delta H_{v}$ - heat of vaporization, $\mathrm{J} / \mathrm{kg} ; M$ - molecular mass, $\mathrm{kg} / \mathrm{mol} ; V_{M n}, V_{M{ }^{-}}$molar volumes of liquid and vaporous phases, $\mathrm{m}^{3} / \mathrm{mol}$.

Solving equation 8 relatively to $V_{M n}$, we'll receive the following dependency:

$V_{M n}=\frac{L_{p c h}}{\frac{L_{p c h}}{V_{\text {мж }}}-\left(\frac{\Delta H v}{M}\right)^{4 / 5}}, \mathrm{~m}^{3} / \mathrm{mol}$

The input data and the results of calculating $D_{\kappa c}$ are given in Table-1.

\section{RESULTS AND DISCUSSIONS}

Since there's no detailed theory of liquid aggregate state, it is still impossible to describe the diffusion mechanism in liquids. The attempts to develop a theoretically sound method of calculating the kinematic diffusion coefficient in liquids didn't provide satisfactory results [10]. Due to the fact that physicochemical properties of plant juice and water are similar, semi empirical methods of calculating the diffusion coefficient in binary mixtures can be used to calculate diffusion of the liquid phase of the chemical preparation in the juice of plants. 
www.arpnjournals.com

Table-1. The calculated values of the vapor diffusion coefficients of various chemical preservatives in plant materials.

\begin{tabular}{|c|c|c|c|c|c|c|c|c|}
\hline $\begin{array}{c}\text { Name of } \\
\text { chemical } \\
\text { preservative }\end{array}$ & $\begin{array}{c}\text { The } \\
\text { density of } \\
\text { the } \\
\text { solution } \\
J_{\text {aqua }} \mathrm{kg} / \mathrm{m}^{3} \\
\end{array}$ & $\begin{array}{c}\text { The } \\
\text { density of } \\
\text { the } \\
\text { solution } \\
J_{I} \mathrm{~kg} / \mathrm{m}^{3} \\
\end{array}$ & 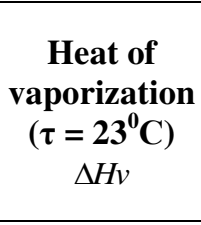 & $\begin{array}{c}\text { Lioparahor } \\
L_{P c h}\end{array}$ & $\begin{array}{c}\text { Molar } \\
\text { volume of } \\
\text { steam }_{V_{M n} \cdot 10^{6}}\end{array}$ & $\begin{array}{c}\text { Molar } \\
\text { volume of } \\
\text { liquid } \\
V_{M c c} \cdot 10^{6}\end{array}$ & 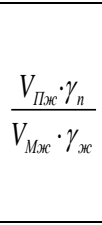 & $\begin{array}{c}\text { Coefficient } \\
D_{x c}, \mathrm{~m}^{2} / \mathrm{s}\end{array}$ \\
\hline AIV-2000 + & 1049 & 2,4 & 352 & 11,8 & 59 & 57 & 0,25 & 7 \\
\hline $\begin{array}{l}\text { Propionic } \\
\text { acid }\end{array}$ & 992 & 2,9 & 364 & 13,7 & 71 & 75 & 0,28 & 6 \\
\hline
\end{tabular}

According to the theory of absolute speed of processes developed by Eyring, the molecules of the diffusing substance penetrate into the spaces (holes) between the molecules of the solvent [10]. In this connection the kinematic diffusion coefficient can be defined as follows:

$D=\left(\frac{V_{M}}{N_{o}}\right)^{2 / 3}\left(\frac{k T}{h}\right) \mathrm{e}^{\frac{\Delta S}{k}} e^{-\frac{\Delta H}{R T}}, \mathrm{~m}^{2} / \mathrm{s}$

where $V_{M}$ - molar volume of the solvent, $\mathrm{m}^{3} / \mathrm{mol} ; T$ absolute temperature ${ }^{\circ} \mathrm{K} ; \Delta S$ - entropy of activating the diffusion process; $\Delta H$ - heat of activation of the process, J/kg; $N_{o}$ - Avogadro number; $k$ - Boltzmann constant; $h$ - Plank constant; $R$ - gas constant.

Based on the findings of statistical mechanics, Kamal and Kanjar developed a formula for calculating $D$ coefficients with the average error of $13 \%$ [8]:

$D=\frac{\left\{\left[1,6\left(\frac{U_{o}}{U}\right)+2,56\left(\frac{U_{o}}{U}\right)^{2} G\right]\left(\frac{U_{o}}{U}\right)^{2 / 3}\right\} 6,19 \cdot 10^{-5}\left(\frac{T}{M}\right)^{1 / 2} V_{0}^{1 / 3}}{24 L_{\text {ucn }}-39 R T}$,

where: $G=1+2.5\left(\frac{U_{o}}{U}\right)+4.5864\left(\frac{U_{o}}{U}\right)^{2}$

$L_{u c n^{-}}$heat of evaporation of the dissolved substance at the temperature $\mathrm{T},{ }^{\circ} \mathrm{K} ; M$ - molecular weight, $\mathrm{kg} ; R$ - gas constant; $U_{0}$ - volume of one mole, $\mathrm{m}^{3} ; U$ - full volume for one molecule, $\mathrm{m}^{3} ; V$ - volume occupied by one molecule, $\mathrm{m}^{3}$.

Based on semi empirical methods of calculating kinematic diffusion coefficient in liquids a number of authors obtained the following basic dependencies of coefficient D.

Kinematic diffusion coefficient $\mathrm{D}$ of the dissolved substance 1 in the solvent 2 at the temperature of $20^{\circ} \mathrm{C}$ according to Arnold equals $[10,11]$ :

$D_{1}=\frac{0.01}{A_{1} A_{2} \mu_{2}^{1 / 2}\left(\mathrm{~V}_{M 1}^{1 / 3}+\mathrm{V}_{M 2}^{1 / 3}\right)^{2}}\left(\frac{M_{1}+M_{2}}{M_{1} M_{2}}\right)^{1 / 2}, \mathrm{~m}^{2} / \mathrm{c}$ where $A_{1} A_{2}$ - correction coefficients characterizing substances 1 and $2 ; \mu_{2}$ - dynamic coefficient of the viscosity of the solvent, $\mathrm{Pa} \cdot \mathrm{s} ; \mathrm{V}_{M 1}, \mathrm{~V}_{M 2}$ - molar volumes of dissolved substance 1 and solvent 2 calculated by summation of fractions according to Leba (Shishatsky et al., 2014), mole $/ \mathrm{m}^{3} ; M_{1}, M_{2}$ - molecular weight of substances 1 and $2, \mathrm{~kg}$.

Wilke and Chang, offered the following dependency [9]:

$D_{1,2}=\frac{7,4 \cdot 10^{-8}(\mathrm{xM})^{1 / 2} T}{\mu V_{M}^{0.6}}, \mathrm{~m}^{2} / \mathrm{c}$

Where $\mathrm{M}$-molecular weight of the diffusing substance, $\mathrm{kg} / \mathrm{mole}$;

$\mu$ - dynamic coefficient of viscosity, $\mathrm{Pa} \cdot \mathrm{s} ; \mathrm{X}$ - coefficient characterising the process of association in the solvent (for water $\mathrm{x}=2.6$ ).

For similar values of molar volumes of the diffusing substanceand the solvent Scheibel suggested the following equation [10]:

$D_{A B}=8.2 \cdot 10^{-8} \frac{T\left[1+\left(\frac{3 V_{M B}}{V_{M A}}\right)^{2 / 3}\right]}{\mu V_{M A}}, \mathrm{~m}^{2} / \mathrm{s}$

For water

$D=\frac{25.2 \cdot 10^{-8} T}{\mu V_{M A}^{1 / 3}}, \mathrm{~m}^{2} / \mathrm{s}$

The error of calculations in the case of using water as a solvent is $\pm 9 \%$ [12].

For water solutions Otmerand Thaker [1] suggested a formula in the range of temperatures $t>$ $20.5^{\circ} \mathrm{C}$.

$D_{B}=\frac{14 \cdot 10^{-9}}{\mu_{B}^{1.1} V_{M}^{0.6}}$, 
www.arpnjournals.com

where $D_{B}$ - diffusion coefficient in the diluted water solution at $\mathrm{t}=20^{\circ} \mathrm{C}, \mathrm{m}^{2} / \mathrm{s} ; \mu_{B}$ - dynamic coefficient of water viscosity at $\mathrm{t}=20^{\circ} \mathrm{C}$.
The results of calculating kinematic diffusion coefficients for chemical preservatives in a liquid medium are presented in Table- 2 .

Table-2. The results of the calculation of the kinematic diffusion coefficients for chemical preservatives in a liquid medium.

\begin{tabular}{|c|c|c|c|c|c|c|c|c|c|c|c|c|c|}
\hline \multirow[t]{2}{*}{$\begin{array}{c}\text { Name of } \\
\text { chemical } \\
\text { preservative }\end{array}$} & \multirow[t]{2}{*}{$\begin{array}{l}\text { Solubility } \\
\text { in water }\end{array}$} & \multicolumn{3}{|c|}{$\begin{array}{c}\text { The density of the solution } \\
J \mathscr{~} \mathbf{k g} / \mathrm{m}^{3} \text { at a } \\
\text { concentration } \%\end{array}$} & \multicolumn{3}{|c|}{$\begin{array}{c}\text { The molecular } \\
\text { weight of the } \\
\text { solution M } 10^{3} \text {, } \\
\text { kg/mol at a } \\
\text { concentration \% }\end{array}$} & \multicolumn{3}{|c|}{$\begin{array}{c}\text { The molar } \\
\text { volume of the } \\
\text { solution Vzh } 10^{6}, \\
\mathrm{~m}^{3} / \mathrm{mol} \text { at a } \\
\text { concentration \% }\end{array}$} & \multicolumn{3}{|c|}{$\begin{array}{c}\text { The diffusion } \\
\text { coefficient D } 10^{9}, \\
\mathrm{~m}^{2} / \mathbf{s} \text { at a } \\
\text { concentration } \%\end{array}$} \\
\hline & & 90 & 60 & 30 & 90 & 60 & 30 & 90 & 60 & 30 & 90 & 60 & 30 \\
\hline AIV-2000+ & + & 1049 & 1030 & 1015 & 60 & 44 & 31 & 57 & 42 & 30 & 1,2 & 1,5 & 1,8 \\
\hline Formic acid & + & 1220 & 1132 & 1066 & 46 & 35 & 26 & 38 & 31 & 25 & 1,6 & 1,8 & 2,0 \\
\hline
\end{tabular}

\section{CONCLUSIONS}

Liquid chemical preservatives, which are, as a rule, organic volatile compounds belonging to carboxylic acid have a considerable fugacity of vaporization. Therefore, after introducing a certain mass of liquid into the plant material there are two simultaneous processes of diffusion: diffusion of vapors of acids into the air spaces of plant material, and diffusion of liquid phase of the preservative into the stalks of the plants.

It has been stated that the relation between vaporous and liquid phases of chemical preservatives can be characterized by the following data: formic acid $0.16 \%$, AIV 2000 Plus - 0.28, propionic acid - 0.25.

$$
\text { Kinematic diffusion coefficient } D_{1,2} \text {, }
$$

characterizing the process of distributing preservatives in the stalks of the plant mass is a constant value defining the complex (effective) distribution of vaporous and liquid phases of the preservative. The numerical value of this coefficient is within the limits between the values of the diffusion coefficients of vapor and liquid. Since there are no numeric values of diffusion coefficients of preservatives in literature sources, it is necessary to carry out an experimental research to define them. Subsequently, using the diffusion coefficient in mathematical modelling of the preservative action in the plant material will make it possible to define the character of changing the preservative concentration in the plant material, and then define the parameters of the equipment performance.

\section{REFERENCES}

[1] Zykov A.V. 2019. The effect of applying liquid preservatives on conservation of nutrients in grass feeds. International research journal. 9-1(87): 52-55. doi.org/10.23670/IRJ.2019.87.9.008

[2] Zykov A.V., Zakharov A.M., Yunin V.A. 2018. The efficiency of applying chemical preservatives with fodder grasses, pressed into rolls. Technologies and technical means of mechanized crop and livestock production. (96): 138-145. doi.org/10.24411/01315226-2019-10130

[3] Salinš A., Freimanis M., Truhanovs R. \& Priekulis J. 2012. The most efficient solutions of forage distribution on modern dairy cow farms. Agronomy Research Biosystem Engineering. (Special Issue 1): 219-226.

[4] Zykov A.V., Zakharov A.M., Yunin V.A. 2019. The efficiency of chemical preservatives in the preparation of hay of high humidity pressed into rolls. Technologies and technical means of mechanized crop and livestock production. (98): 133-140. doi.org/10.24411/0131-5226-2018-10067

[5] Coblentz W.K., Bertram M.G. 2012. Effects of a propionic acid-based preservative on storage characteristics, nutritive value, and energy content for alfalfa hays packaged in large round bales. Journal of Dairy Science. 95(1): 340-352, ISSN 0022-0302, doi.org/10.3168/jds.2011-4496

[6] Baah J., McAllister T., Bos L., Van Herk F., Charley R. 2005. Effect of Lactobacillus buchneri 40788 and Buffered Propionic Acid on Preservation and Nutritive Value of Alfalfa and Timothy Highmoisture Hay. Asian-Australas J Anim Sci. 18(5): 649-660. DOI: doi.org/10.5713/ajas.2005.649

[7] Potashnikov P.F., Komarova L.Yu. 2012. Using the Brunauer-Emmett-Teller method for analyzing the internal structure of packaging cartons. Bulletin of the 
Ivan Fedorov Moscow State University of Printing Arts. (12): 114-119.

[8] Novoselov A.G. 2014. Molecular diffusion of gases in liquid. Coefficients of molecular diffusion of carbon dioxide in water. Scientific journal of the National Research University of information technologies, mechanics and optics. Series: Processes and devices of food production. (2): 19.

[9] Shishatsky Yu. I., Plyukha S. Yu., Ivanov S.S. 2014. Determining the diffusion coefficients of extractive substances in lupine. Bulletin of the Voronezh State University of Engineering Technologies. (2): 28-32.

[10] Valge A.M., Sukhoparov A.I. 2018. Evaluation of the efficiency of technological processes of forage preparation from grasses. Technologies and technical means of mechanized crop and livestock production. 3(96): 129-138. doi.org/10.24411/0131-5226-201810066

[11] Kahr H., Pointner M., Krennhuber K., Wallner B. \& Jäger A. 2015. Lipid production from diverse oleaginous yeasts from steam exploded corn cobs. Agronomy Research. 13(2): 318-327.

[12] Galkin V.S. 2007. Transformation of the first approximation equations by the Chapman-Enskog method and vector transfer relations for mixtures of multicomponent gases. Applied mathematics and mechanics. 71(2): 301-302. 